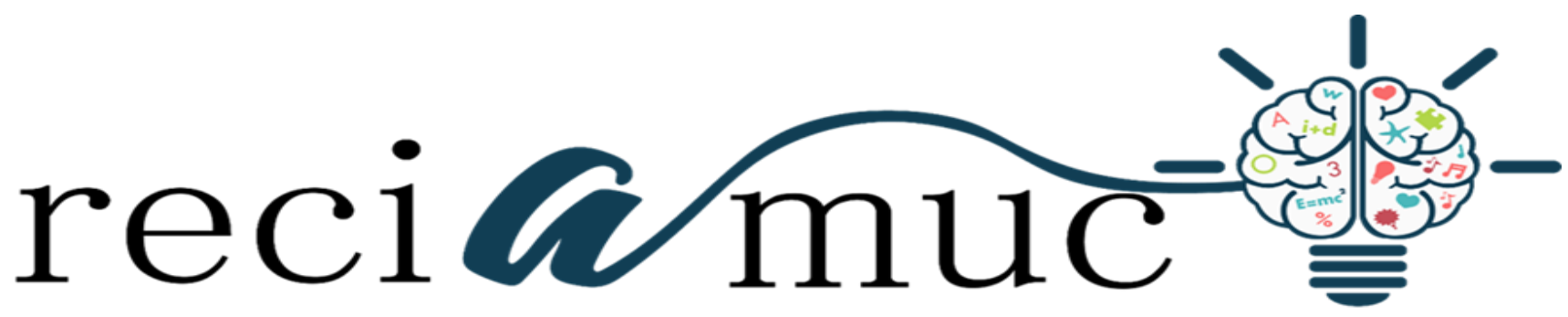

Revista científica de investígación actualización del mundo de las ciencias

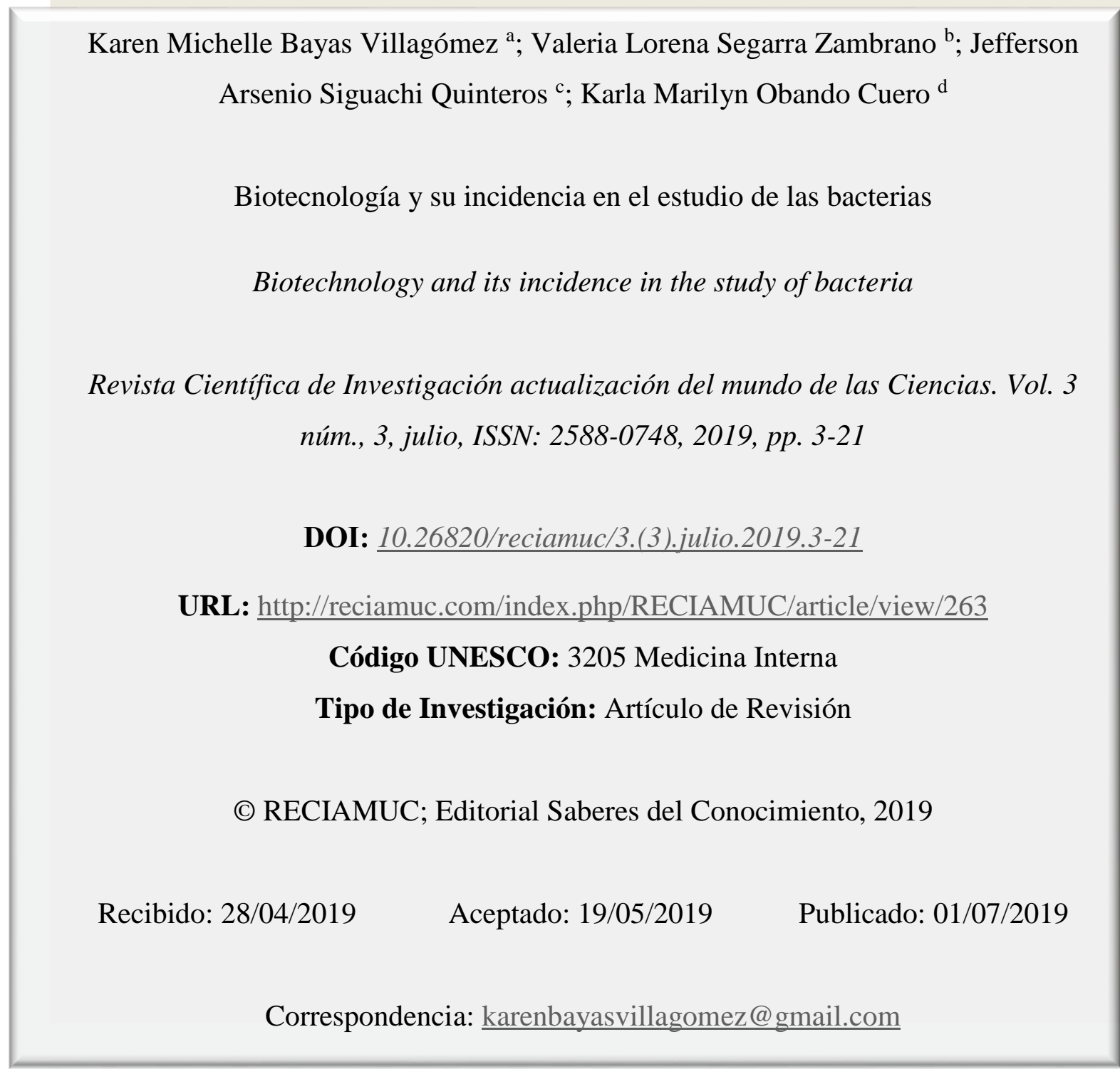

a. Médica; Investigador Independiente; Guayaquil, Ecuador; karenbayasvillagomez@gmail.com

b. Médica; Investigador Independiente; Guayaquil, Ecuador; valery_1sz@hotmail.com

c. Médico; Investigador Independiente; Guayaquil, Ecuador; jeferson_siguachi@hotmail.com

d. Medico; Investigador Independiente; Guayaquil, Ecuador; karla_8492@hotmail.com 


\section{Biotecnología y su incidencia en el estudio de las bacterias}

Vol. 3, núm. 3., (2019)

Karen Bayas Villagómez; Valeria Lorena Segarra Zambrano; Jefferson Arsenio Siguachi

Quinteros, Karla Marilyn Obando Cuero

\section{RESUMEN}

El avance alcanzado por los científicos en el área de la microbiología, permite ofrecer a las ciencias de la salud nuevas evidencias en cuanto a las bacterias se refiere, este progreso, da a la población en general oportunidades viables para mejorar posibles enfermedades estrechamente vinculadas con la presencia de microorganismos, que requieren la aplicación de antibióticos para propiciar la respectiva recuperación del paciente. Ante estas ideas, la biotecnología se convierte en una herramienta innovadora, que ayuda a integrar diferentes enfoques tecnológicos, cuya aplicación en las ciencias biológicas hace posible el manejo de enfermedades. Al respecto, Regollo (2016) destaca la biotecnología en el campo de la medicina "permite detectar y prevenir enfermedades antes de que se manifiesten". (p.6). Según lo citado, su incorporación en las ciencias médicas representa una vía que garantiza la identificación de los genes que intervienen en las enfermedades con más prevalencia y así, desarrollar fármacos que compensen la actividad de los genes alterados en cada patología. Asimismo, ayuda al estudio de los agentes infecciosos, mediante la utilización de microorganismos inocuos en las vacunas, que hacen posible introducir genes que determinan la producción de antígenos en bacterias inocuas que constituyen en sí las mismas vacunas, esto hace que el individuo vacunado pueda generar los anticuerpos necesarios para así llegar a su recuperación total. Apreciaciones de significación para el desarrollo del presente artículo cuyo propósito es analizar la biotecnología y su incidencia en el estudio de las bacterias, planteamiento que lo ubica en el campo de las investigaciones documentales. Para luego, indicar a través de las conclusiones las apreciaciones generales del investigador relacionadas con los eventos que caracterizan el tema seleccionado.

Palabras Claves: Biotecnología; Estudio de las bacterias; Microbiología. 


\title{
Biotecnología y su incidencia en el estudio de las bacterias
}

Vol. 3, núm. 3., (2019)

Karen Bayas Villagómez; Valeria Lorena Segarra Zambrano; Jefferson Arsenio Siguachi

Quinteros, Karla Marilyn Obando Cuero

\begin{abstract}
The progress achieved by the scientists in the area of Microbiology, offers new evidence referred to in terms of bacterium, this progress to the health sciences, gives the population in general viable opportunities to improve possible diseases closely linked to the presence of microorganisms, requiring the application of antibiotics to promote the respective patient recovery. To these ideas, the biotechnology becomes an innovative tool, which helps to integrate different technological approaches, whose application in the life sciences makes possible the management of diseases.In this regard, Regollo (2016) highlights biotechnology in the field of medicine "can detect and prevent diseases before they appear". (p.6). As cited, its incorporation in the medical sciences represents an approach that ensures the identification of genes involved in diseases with more prevalence and therefore develop drugs that compensate for the altered gene activity in each pathology. Also, aid to the study of infectious agents, through the use of harmless microorganisms in vaccines, which make it possible to introduce genes that determine the production of antigens in harmless bacteria that constitute in itself the same vaccines, this it makes that the vaccinated individual can generate the antibodies needed to reach its full recovery. Appreciations of significance for the development of this article whose purpose is to discuss biotechnology and its impact on the study of bacterium, approach which places him in the field of documentary research. Then, through the findings indicate general appreciations of the researcher related to the events that characterize the selected topic.
\end{abstract}

Key Words: Biotechnology; Study of bacteria; Microbiology. 


\section{Biotecnología y su incidencia en el estudio de las bacterias \\ Vol. 3, núm. 3., (2019) \\ Karen Bayas Villagómez; Valeria Lorena Segarra Zambrano; Jefferson Arsenio Siguachi \\ Quinteros, Karla Marilyn Obando Cuero}

\section{Introducción.}

Durante la evolución de la especie humana, la biotecnología ha tenido importancia para la conservación de los alimentos, que posteriormente utilizaban para su consumo, es así como, en la época actual se incorpora como una herramienta tecnológica que sirve de apoyo para el desarrollo biológico y su modelamiento molecular. En tal sentido, la Convención de Diversidad Biológica (1992), define a la biotecnología como "toda aplicación tecnológica que utilice sistemas biológicos y organismos vivos o sus derivados para la creación o modificación de productos o procesos para usos específicos" (p.58). Según la definición, se puede indicar que esta nueva herramienta tecnológica al ser empleada en los sistemas biológicos y organismos vivos, permite ofrecerles a las ciencias de la salud, la incorporación de medicamentos especiales para cada patología diagnosticada y así asegurar, el bienestar integral del paciente.

En consecuencia, la microbiología se convierte en una disciplina de importancia, pues, permite a través del estudio de los microorganismos conocer a profundidad el origen celular, su desarrollo y forma de actuar en el organismo para evolucionar en su estudio y volcar las virtudes de estos en la ciencia médica, esta es una las razones por la cual biotecnología se dedica al estudio de los organismos más pequeños, quienes han dado aportes significativos a la salud. De igual manera, se puede acotar que, la biotecnología se apoya en varias ciencias entre ellas: la biología, química, bioquímica, fisiología, física, farmacia, medicina, ingeniería genética e inmunología, esta unión multidisciplinaria logra un alcance mayor y una perspectiva de la salud en forma integral para mejorar el diagnóstico y su tratamiento, al desarrollar nuevos abordaje terapéutico como: producción de proteínas recombinantes, terapia celular, nuevas vacunas, área identificada como biotecnología roja por integrar varias disciplinas destacadas: sector farmacéutico, tecnologías médicas e investigación biomédica.

Al tomar en consideración estas ideas, es relevante citar los trabajos de investigación en los procesos de inmunización pioneros son los de E. Jenner y L. Pasteur (primeras nociones de vacunas y sus aplicaciones) otros aportes de gran importancia para la biotecnología roja fue el descubrimiento de la penicilina por Flening (1928), desciframiento del código genético (1958-61), descubrimiento de los plásmidos y técnicas de ADN recombinante. También se suman a estos 


\section{Biotecnología y su incidencia en el estudio de las bacterias}

Vol. 3, núm. 3., (2019)

Karen Bayas Villagómez; Valeria Lorena Segarra Zambrano; Jefferson Arsenio Siguachi

Quinteros, Karla Marilyn Obando Cuero hallazgos la producción de la somatotropina (1977), comercialización de la insulina (1982), con datos recientes en el 2001 se hace pública la secuencia del genoma humano y se identifican más de 200 genes que a futuro facilitó el desarrollo de nuevos productos biotecnológicos.

De acuerdo con lo citado, se puede entender que la biotecnología aporta nuevas herramientas diagnósticas especialmente útiles para los microorganismos que son difíciles de cultivar, esto, permite su identificación sin necesidad de aislarlo lo cual es más rápido que en el pasado cuando eran estudiados mediante métodos microbiológicos y pruebas químicas que son más tediosas de realizar. Esto, facilita la introducción del concepto diagnóstico rápido, sensible y preciso lo cual es un logro de importancia para esta ciencia. Asimismo, desarrolla una nueva disciplina denominada patología molecular, encargada de estudiar alteraciones genéticas y bioquímicas del tumor a diferencias de la anatomía patológica que lo hace a través de la morfología del mismo. Esta diferencia determina alternaciones celulares tempranas que permiten un tratamiento oportuno y maximiza la respuesta a la cura.

En razón de lo anterior, se puede decir que las pruebas para la detección de patógenos en el cuerpo evolucionan gracias a la biotecnología, los nuevos avances en la biología molecular, secuenciación genómica y proteica permite aportar nuevas y mejores pruebas diagnósticas altamente específicas y de gran rendimiento. Con una alta sensibilidad, patrones de reconocimiento y nuevas técnicas inmunológicas seguras, que podrán pronto superar la necesidad de producir anticuerpos mediante la inmunización. Aunque estos métodos requieren instrumentación compleja, puede anticiparse que pronto serán accesibles para su aplicación en salud pública.

Al respecto, Cabrera (2016) destaca que en el campo del estudio de las bacterias "tiene relevancia al desarrollar nuevas técnicas de aislamiento bacteriano, además de procesos para la obtención de productos biológicos que permiten eficacia terapeuta como las vacunas, antibióticos e insulinas." (p.54). Es decir, mediante la implementación de la biotecnología, las ciencias médicas, tienen oportunidad de ofrecer a sus pacientes fármacos confiables que le ayudan a combatir las enfermedades y por ende reducir el impacto en la morbimortalidad de la población.

Con el fin de ampliar las consideraciones anteriores, se cita los datos expuestos por, el Centro para el Control y Prevención de Enfermedades (2015) "las enfermedades trasmitidas por los alimentos 


\section{Biotecnología y su incidencia en el estudio de las bacterias}

Vol. 3, núm. 3., (2019)

Karen Bayas Villagómez; Valeria Lorena Segarra Zambrano; Jefferson Arsenio Siguachi

Quinteros, Karla Marilyn Obando Cuero

constituyen una carga importante para la salud pública, en Estados Unidos de los 31 microorganismos conocidos provocan anualmente 9,4 millones enfermedades, 55,961 hospitalizaciones y 1.351 muertes" (p.12). De acuerdo con estas apreciaciones, se puede entender que, la contaminación que registran los alimentos por la presencia de microorganismos, conduce a elevar la presencia de enfermedades, hospitalizaciones y hasta la muerte, de allí, la incidencia que tiene la biotecnología en el estudio de las bacterias, gracias a su actuación, se puede agregar a nivel de la salud pública cambios importantes en dicha problemática.

En esta misma dirección, la Organización Mundial de la Salud (2018) a través del nuevo Sistema Mundial de Vigilancia de la Resistencia a los Antimicrobianos denominado GLASS "ha revelado la presencia generalizada de resistencia a los antibióticos en muestras de 500000 personas de 22 países en las que se sospechaban infecciones bacterianas" (p.10). Según, este planteamiento, se puede decir que, el consumo de alimentos puede generar en la población, enfermedades estrechamente relacionadas con las bacterias, situación que hace posible generalizarse entre los individuos, debido a la falta de higiene que se debe considerar durante la manipulación de los alimentos, con el fin de evitar la propagación de estos microorganismos.

De igual manera, Ochoa y Padilla (2015) las infecciones bacterianas representan:

Una complicación grave y frecuente de la cirrosis hepática con una alta morbimortalidad y, además, tienen una incidencia elevada comparada con la población general. Son una de las causas más frecuentes de hospitalización y principal razón de la progresión y complicaciones de esta enfermedad. (p.11)

De acuerdo con lo indicado por Ochoa y Padilla, muestra que la presencia de las enfermedades, ocasionadas por infecciones se convierten cada día en una realidad que amerita, ser analizada con el fin de gestionar mediante investigaciones sus causas e introducir los respectivos correctivos a través de antibióticos modernos, que lo logren cambiar el nivel de resistencia que presenta el microorganismo y así propiciar, cambios importantes en las estadísticas relacionadas con la presencia de bacterias que generan complicaciones en los pacientes. 


\section{Biotecnología y su incidencia en el estudio de las bacterias}

Vol. 3, núm. 3., (2019)

Karen Bayas Villagómez; Valeria Lorena Segarra Zambrano; Jefferson Arsenio Siguachi

Quinteros, Karla Marilyn Obando Cuero

Estos datos expuestos en el discurso, llevan a destacar la significación que posee en la actualidad la biotecnología; pues, mediante su incorporación en el estudio de las bacterias, se hace posible no sólo fabricar antibióticos que reduzcan la resistencia de los microorganismos, sino que, agrega nuevas informaciones relevantes para vigilar, controlar, diagnosticar y buscar alternativas que eleven las probabilidades de atención del paciente al presentar alguna enfermedad vinculada con infecciones bacterianas. Además, se puede resaltar que, las apreciaciones son las encargadas de direccionar el camino teórico del presente artículo, sus valoraciones estarán enmarcadas en la revisión documental como aporte bibliográfico de significación para el análisis correspondiente a la biotecnología y su incidencia en el estudio de las bacterias.

\section{Método.}

Los procedimientos metodológicos que caracterizan a las investigaciones documentales, parten de la revisión bibliográfica, mediante ellas, se tiene oportunidad de evaluar los contenidos preestablecidos y orientar la práctica investigativa hacia el alcance del propósito previamente considerado. Por lo tanto, para darle la respectiva ubicación al artículo se precisa la necesidad de seleccionar el método. Al respecto, Barrera (2017) lo define como "un evento previo encargado de estimar las condiciones reales para cumplir con el desarrollo de un estudio en cualquier contexto investigativo". (p.52)

De lo antes citado, se precisa que mediante la selección del método se puede organizar el contenido de un proceso investigativo, desde una perspectiva científica que garantiza su ejecución en función a las necesidades del autor. En consecuencia, este artículo, toma en consideración el método comparativo, pues, su utilización hace posible el desarrollo de cada uno de los aspectos esenciales para exponer nuevas ideas en el marco temático de la biotecnología y su incidencia en el estudio de las bacterias. Tal como lo expresa, Carreño (2018) el método comparativo "permite establecer no sólo semejanzas, sino que ayuda a identificar aquellas posibles diferencias importantes para adecuar las conclusiones en un campo científico". (p.65). 


\section{Biotecnología y su incidencia en el estudio de las bacterias \\ Vol. 3, núm. 3., (2019) \\ Karen Bayas Villagómez; Valeria Lorena Segarra Zambrano; Jefferson Arsenio Siguachi \\ Quinteros, Karla Marilyn Obando Cuero}

\section{Tipo de Investigación.}

El desarrollo investigativo, propuesto a través del método asegura con firmeza el desarrollo de cada aspecto esencial para generar nuevas situaciones vinculadas con el tema que caracteriza a este artículo. Es así como, Saavedra (2018) precisa que mediante la investigación documental "le permite al investigador adecuar sus apreciaciones en función a las situaciones propuestas para la revisión bibliográfica". (p.74). Por lo tanto, esta apreciación permite asegurar que mediante la revisión del material identificado con los elementos que caracterizan a este problema de indagación, como la biotecnología y su incidencia en el estudio de las bacterias.

\section{Técnicas Documentales.}

Dentro del marco de las ideas, que estiman la conducción de este proceso investigativo, necesita la selección adecuada en cuanto al uso de las técnicas documentales que darán cabida a nuevas actuaciones como parte esencial del proceso investigativo. En este sentido, Saavedra (ob.cit) "son herramientas válidas para la investigación documental, como parte esencial del proceso indagatoria y así cumplir con la redacción del contenido previamente seleccionado por el autor". (p.76). Es decir, el uso de las técnicas documentales permite no sólo organizar los contenidos a tratar, sino, revisar con precisión y coherencia los diferentes textos complementarios del tema a tratar, como una expresión de cambio en el proceso investigativo.

\section{Técnicas de Recolección de Información.}

Para lograr, una acción investigativa que tengan oportunidad de dirigir las actividades establecidas de manera secuencial, por lo tanto, es relevante la incorporación de las técnicas de recolección de información, como: la lectura que hace posible comprender los diferentes enfoques que caracterizan al tema seleccionado, en consecuencia, se consideran las ideas dadas por Carreño (ob.cit) una técnica para la recolección de información "no más que un proceso selectivo de aspectos generales, encargados de dar flexibilidad al contenido preestablecido, las mismas son dinámicas y ayudan a la organización definitiva de los contenidos que requiere la investigación, para darle la respectiva consistencia y coherencia temática. 


\section{Biotecnología y su incidencia en el estudio de las bacterias}

Vol. 3, núm. 3., (2019)

Karen Bayas Villagómez; Valeria Lorena Segarra Zambrano; Jefferson Arsenio Siguachi

Quinteros, Karla Marilyn Obando Cuero

\section{Resultados.}

El análisis correspondiente al tema seleccionado, permite ampliar sus apreciaciones de manera general, en consecuencia, los aspectos que forman parte de este proceso investigativo, son plasmados de manera secuencial y funcional para así ampliar los criterios básicos que lo estructuran en dos posiciones: biotecnología y estudio de las bacterias.

\section{Biotecnología.}

La biotecnología, desde su surgimiento, tiene como propósito resolver los diferentes problemas del hombre. Esta combina lo más tradicional con lo más novedoso desde los puntos de vista científico y técnico. En su desarrollo según Medrano (2015) precisa que en su transitado desarrollo se encuentran 4 etapas:

- Biotecnología de Primera Generación, Tradicional, Antigua, Empírica o pre Pasteur: abarca los procesos de elaboración de bebidas alcohólicas, pan, vinagre, productos lácteos y alimentos fermentados tradicionales, entre otros, desarrollados mediante prácticas empíricas y se insertan por sí mismas en las actuales fuentes de alimentación humana.

- Biotecnología de Segunda Generación: comprende el estudio de los antibióticos o industrial, los procesos biológicos son controlados para desarrollar favorablemente sus funciones, lo cual constituye la esencia de esta etapa. Se desarrolla a partir de la segunda mitad del siglo XIX, con los conocimientos incipientes de la microbiología y la bioquímica, y culmina con la consolidación de la ingeniería bioquímica, lo que contribuyó a impulsar la incorporación de la técnica de fermentación en algunas áreas industriales.

- Biotecnología de la Tercera Generación: sirve de las técnicas de ADN recombinante o ingeniería genética. Se trata de sistemas novedosos utilizados para alterar o modificar las propiedades genéticas de los organismos de una forma totalmente dirigida, de manera que comienza la denominada biotecnología moderna, la cual brinda a la sociedad en los últimos años una serie de productos verdaderamente útiles, con amplia aceptación, que han revolucionado el diagnóstico y la práctica de la medicina.

- Biotecnología de Cuarta Generación: acelera el descifrado de genomas completos de organismos, lo que unido a la aplicación de la genómica y la proteómica, genera una 


\section{Biotecnología y su incidencia en el estudio de las bacterias}

Vol. 3, núm. 3., (2019)

Karen Bayas Villagómez; Valeria Lorena Segarra Zambrano; Jefferson Arsenio Siguachi

Quinteros, Karla Marilyn Obando Cuero

enorme cantidad de datos que conlleva al surgimiento de la bioinformática y, por tanto, al desarrollo de una nueva plataforma de trabajo en la búsqueda de productos donde la satisfacción del hombre el principal objetivo.

Tal como se ha visto, la biotecnología de tercera y cuarta generaciones han sido motivadas por la necesidad de adquirir nuevos tratamientos médicos, lo cual aporta contribuciones excepcionales a la medicina humana y favorece el avance de la ciencia, cuyo progreso establece el paso hacia la denominada medicina personalizada. Los avances en el campo de la biotecnología, especialmente del proyecto genoma humano, desarrollo de la investigación científico-técnica, además de una serie de estrategias y tecnologías novedosas como las denominadas ómicas (genómica, proteómica y farmacogenómica, entre otras), así como la bioinformática, han iniciado un proceso de transformación en el que la acción terapéutica se centra sobre el paciente (individuo) que sufre una enfermedad, más que sobre la enfermedad sufrida por el paciente. Por lo tanto, el elemento fundamental es el individuo, de ahí que esa individualidad ha implementado la llamada medicina personalizada.

$\mathrm{Al}$ analizar las ideas anteriores, se precisa que la medicina personalizada persigue sus objetivos desde una perspectiva individualizada, pero no para cada persona, sino para grupos de individuos con características genéticas similares (tratamientos segmentados). Esta trata de entender la enfermedad molecularmente; comprender cómo se produce la respuesta a los tratamientos; particularizar dicha respuesta; predecir el riesgo individual de padecer la enfermedad o de responder a un medicamento; diagnosticar correctamente y mejorar el tratamiento para optimizar la eficacia de los fármacos, minimizar los efectos adversos para así lograr el esperado éxito terapéutico. Teniendo en cuenta lo anterior, en el presente artículo los autores tratan de analizar la biotecnología y su incidencia en el estudio de las bacterias.

Asimismo, Sasson (2015) define a la biotecnología "como aquella área que se relaciona en el uso de un organismo o de algún componente de un organismo u otro sistema biológico, para hacer un producto o proceso con el fin particular". (p.39). Según lo citado, se precisa que mediante la incorporación de la biotecnología, las ciencias médicas logran obtener nuevas informaciones en cuanto a los microorganismos y así agregar a la vida del paciente ante una enfermedad su cura. 


\section{Biotecnología y su incidencia en el estudio de las bacterias}

Vol. 3, núm. 3., (2019)

Karen Bayas Villagómez; Valeria Lorena Segarra Zambrano; Jefferson Arsenio Siguachi

Quinteros, Karla Marilyn Obando Cuero

De igual manera, se encuentra la terapia génica que es una novedosa técnica usada en el tratamiento de trastornos genéticos causados por un gen no funcional. Esta terapia funciona administrando el ADN del gen que les falta a las células del cuerpo. Por ejemplo, en el trastorno genético fibrosis quística, las personas carecen de la función de un gen de un canal de cloruro producido en los pulmones. En un ensayo clínico reciente de terapia génica, se insertó una copia del gen funcional en una molécula de ADN circular llamada plásmido y se suministró a las células pulmonares de los pacientes en esferas de membrana (en forma de un aerosol). En este ejemplo, el uso de los componentes biológicos de diferentes fuentes (un gen de seres humanos y un plásmido de bacterias) para obtener un nuevo producto que ayuda a preservar la función pulmonar en pacientes con fibrosis quística.

Cabe agregar, que los procesos científicos que caracterizan el desarrollo de la biotecnología se encuentran los trabajos relacionados con la clonación de $\mathrm{ADN}$, actividades caracterizadas por hacer muchas copias de un fragmento de ADN de interés, como un gen. En muchos, casos, la clonación de ADN consiste en insertar un gen blanco en una molécula de ADN circular llamada plásmido. El plásmido puede replicarse en bacterias para producir muchas copias del gen de interés. En otros, el gen también se expresa en las bacterias y se fabrica una proteína (como la insulina que usan los diabéticos).

Figura $\mathbf{N}^{\circ} 1$ Clonación del ADN

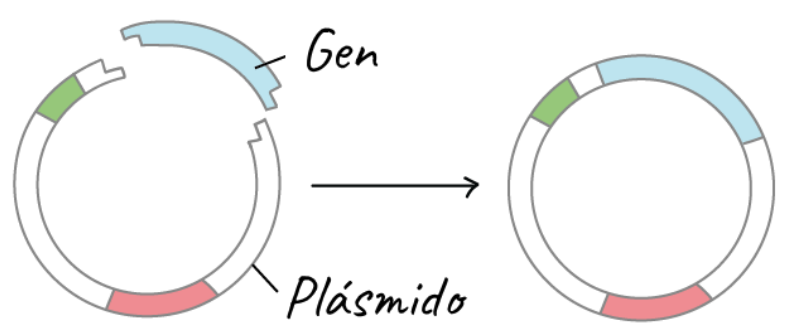

Fuente: Sasson (ob.cit)

Otro ejemplo de significación en materia de biotecnología, para la medicina y el tratamiento de las bacterias, es el uso de la penicilina que ha tenido una importante actuación, al utilizar ciertas especies de moho que producen el antibiótico penicilina. Para obtener las pequeñas cantidades de 


\section{Biotecnología y su incidencia en el estudio de las bacterias}

Vol. 3, núm. 3., (2019)

Karen Bayas Villagómez; Valeria Lorena Segarra Zambrano; Jefferson Arsenio Siguachi

Quinteros, Karla Marilyn Obando Cuero

penicilina que serían usadas en los primeros ensayos clínicos, los investigadores cultivaron hasta 500500500 litros de jugo de moho. El proceso ha mejorado con el paso de los años para la producción industrial con el uso de cepas de moho que son más productivas y con mejores condiciones de cultivo para aumentar los rendimientos. Aquí, se observa el uso de un organismo (el moho) para obtener un producto para uso humano, en este caso, un antibiótico para tratar infecciones bacterianas.

Estos cambios registrados a nivel de la penicilina, permiten a la medicina complementar el trabajo de diagnóstico del paciente, al considerar nuevos fármacos vinculados con el respectivo antibiótico utilizado para combatir las infecciones ocasionadas por la presencia de bacterias en diferentes modalidades, que hacen posible propiciar un cambio en los pacientes ante estas enfermedades que afectan a la población en general.

Figura 2 Imagen Modificada del Hongo de la Penicilina

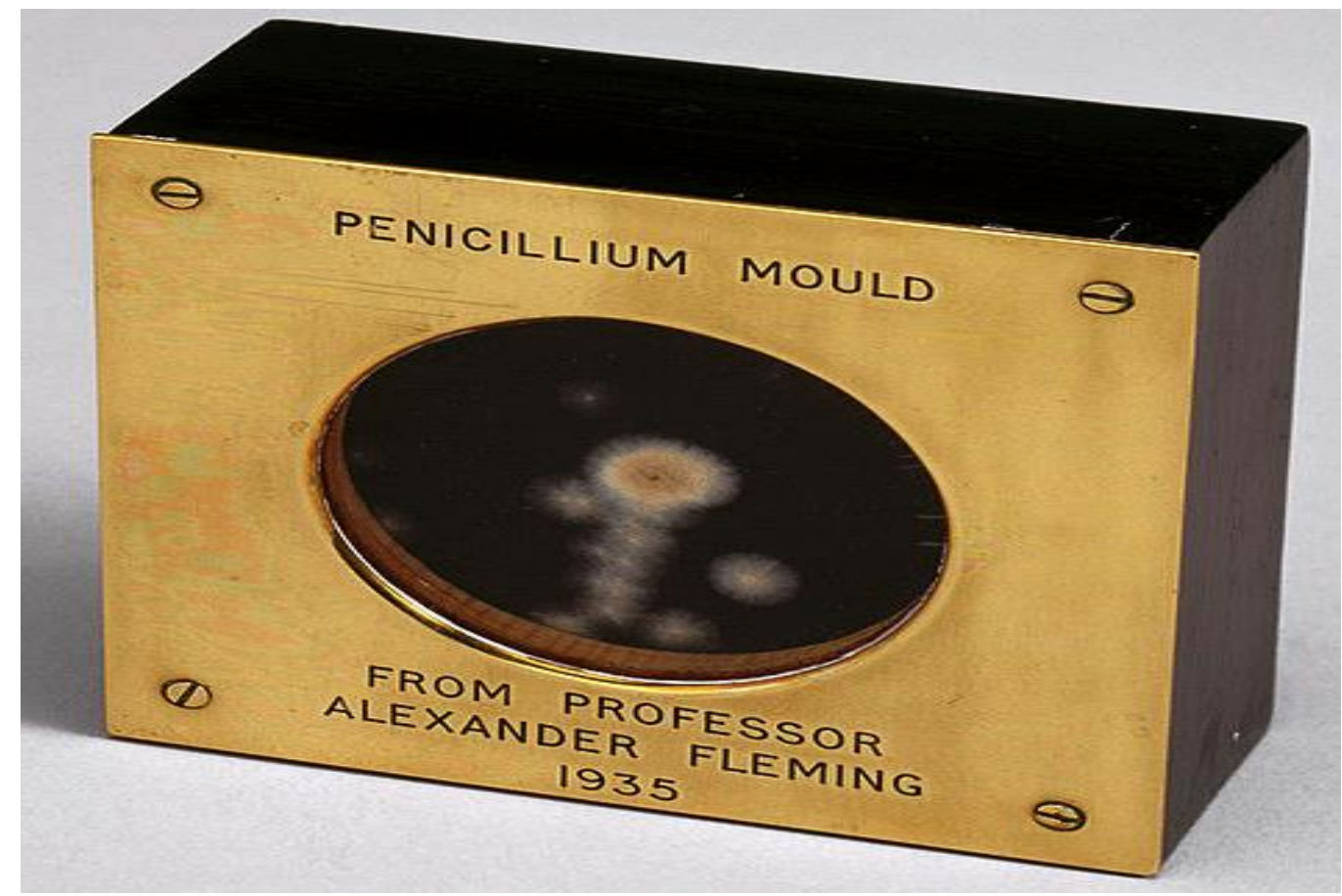

Fuente: Medrano (ob.cit)

En razón de las consideraciones anteriores, se precisa que, mediante la utilización de la biotecnología, revista una incidencia en el estudio de las bacterias, pues, tiene el potencial de 


\section{Biotecnología y su incidencia en el estudio de las bacterias}

Vol. 3, núm. 3., (2019)

Karen Bayas Villagómez; Valeria Lorena Segarra Zambrano; Jefferson Arsenio Siguachi

Quinteros, Karla Marilyn Obando Cuero

proporcionar beneficios a las personas y sociedades, pero también puede tener efectos negativos o consecuencias imprevistas. Esto es cierto para todas las formas de tecnología, no solo para la biotecnología. Sin embargo, puede ofrecer diferentes tipos de beneficios y plantear diferentes tipos de dilemas respecto a otras formas de tecnología.

Es importante que se prueben y analicen cuidadosamente las innovaciones biotecnológicas (como cualquier otra innovación tecnológica) antes de divulgarse para un uso general. Los ensayos clínicos y regulaciones gubernamentales ayudan a asegurar que los productos biotecnológicos puestos en el mercado sean seguros y efectivos. Sin embargo, a veces aparece nueva información que hace reconsiderar a las empresas u organismos gubernamentales la seguridad o la utilidad de una innovación. Esto sucede ocasionalmente, por ejemplo, cuando se retira un medicamento del mercado. Además, las innovaciones biotecnológicas pueden plantear nuevas preguntas éticas sobre cómo deben utilizarse o no el conocimiento, información y técnicas.

\section{Estudio de las Bacterias.}

Las bacterias desempeñan un papel de considerable importancia en la naturaleza. Algunas de ellas cuentan con una actividad enzimática intensa que puede aprovecharse en las industrias de fermentación; en los animales superiores, las bacterias realizan la función de agentes activos en la digestión intestinal. Cierto número de bacterias genera pigmentos (bacilo piociánico); otras formas bacterianas producen gases, depósitos de hierro o de azufre, o bien toxinas excrementadas o integradas al cuerpo celular.

De manera general, las bacterias son los agentes de las fermentaciones y putrefacciones que transforman las materias orgánicas en gases y sustancias inertes aptas para reincorporarse al ciclo vital; además, fijan el gas atmosférico, enriquecen el suelo en nitrógeno y, de este modo, proporcionan a los vegetales algunos alimentos inorgánicos que les son indispensables para el desarrollo. En los ciclos biológicos, en definitiva, las bacterias desempeñan el papel fundamental de descomponedores o mineralizadores. Las bacterias patógenas sólo constituyen una pequeña parte del universo bacteriano.

En relación a lo anterior, Alves (2015) destaca que la célula bacteriana tiene unas dimensiones del orden del "micrómetro o micra (una milésima de milímetro). La talla media de una bacteria oscila 


\section{Biotecnología y su incidencia en el estudio de las bacterias}

Vol. 3, núm. 3., (2019)

Karen Bayas Villagómez; Valeria Lorena Segarra Zambrano; Jefferson Arsenio Siguachi

Quinteros, Karla Marilyn Obando Cuero

entre 1 y 10 micras, si bien existen células «enanas» de 0,2 micras de longitud y células gigantes, cuya longitud alcanza las 500 micras". (p.147). Se hace evidente que presentan un tamaño muy pequeño, que puede ser observado mediante el microscopio, es allí, donde la utilización de la biotecnología asegura la incorporación de estudios más específicos para estimar sus características y actuaciones en campo especial.

Este autor, hace una clasificación de las diferentes enfermedades causadas por las bacterias, entre las cuales cita las siguientes:

Difteria: Está causada por el Corynebacteriumdiphtheriae, un bacilo grampositivo con una característica forma de porra. La difteria se combate mediante la administración de una antitoxina específica, preparada a partir de sangre de animales inmunizados con toxinas químicamente modificadas que presentan baja toxicidad, pero que conservan un elevado poder antigénico.

Tuberculosis: Está producida por el bacilo de Koch, es decir, el Mycobacterium tuberculosis, un bacilo grampositivo que puede desarrollarse en casi todos los tejidos del cuerpo, aunque casi siempre presenta una fase de multiplicación primaria, a menudo exclusiva, en los pulmones. La inmunización con una estirpe avirulenta del bacilo de la tuberculosis (bacilo de Calmette y Guerin o BCG) aumenta la resistencia del sistema inmunitario ante esta enfermedad, que no empezó a ser vencida hasta mediados del siglo XX.

Peste: La peste es una enfermedad producida por un bacilo gramnegativo, la Pasteurellapestis, que se transmite de ordinario de la rata a los humanos mediante la picadura de la pulga. Se propaga también con frecuencia por vía respiratoria, cuando los bacilos, después de alcanzar el torrente circulatorio, infectan los pulmones.

Cólera: Es una enfermedad intestinal grave que se propaga por contaminación con aguas fecales, siendo su control una estricta cuestión de saneamiento, puesto que no se conocen (a diferencia de otras muchas enfermedades bacterianas) portadores crónicos. El cólera es producido por un vibrio, el Vibrio cholerae, que es en realidad el único vibrio patógeno para el hombre. 


\section{Biotecnología y su incidencia en el estudio de las bacterias}

Vol. 3, núm. 3., (2019)

Karen Bayas Villagómez; Valeria Lorena Segarra Zambrano; Jefferson Arsenio Siguachi

Quinteros, Karla Marilyn Obando Cuero

Gonorrea y Sífilis: Otro grupo de enfermedades bacterianas de diverso signo se propagan por contagio directo. Entre ellas la gonorrea o blenorragia, que tiene en el gonococo o Neisseriagonorrhoeae su germen causante. Dicho diplococo gramnegativo invade los tejidos de los órganos sexuales y reproductores y se transmite mediante la relación sexual. Lo mismo ocurre en la sífilis, otra enfermedad de transmisión sexual, más grave aún, causada por una espiroqueta llamada Treponema pallidum.

Tétanos y Gangrena: Parientes próximos del Clostridiumbotulinum e igualmente anaerobios son el Clostridiumtetani y el Clostridiumsepticum responsables, respectivamente, del tétanos y de la gangrena gaseosa, dos enfermedades graves que tienen su vía de entrada en el cuerpo a través de heridas profundas mal desinfectadas.

De lo antes expuesto, se puede encontrar que la ciencia encarada del estudio de las bacterias, se reconoce como la bacteriología, rama de la microbiología dedicada al estudio de las bacterias, constituye en la actualidad una disciplina de importancia para la investigación básica, con un número de aplicaciones tanto industriales (fermentaciones) como sanitarias (veterinaria y medicina). Los laboratorios bacteriológicos forman hoy parte integrante de los hospitales, industrias alimentarias y también de los organismos dedicados al control y protección medioambientales. Al respecto, Calvo (2016) destaca que la bacteriología estudia "la forma, proceso de reproducción, condiciones favorables y desfavorables de vida de los microorganismos bacterianos y su acción patógena sobre el hombre y animales."(p.236)Por lo tanto, los objetivos básicos de la bacteriología médica son delimitar la patogenicidad o capacidad de las bacterias para causar daños o provocar enfermedades y desarrollar remedios terapéuticos, especialmente sustancias biocidas y bacteriostáticas que, sin destruir las bacterias, impiden no obstante su reproducción.

Cabe agregar, que las bacterias que tienen forma esférica u ovoide se denominan cocos, los cuales se tiñen de azul con el Gram, se les llama grampositivos. Cuando los cocos se agrupan en cadenas, se les denomina estreptococos y cuando lo hacen en racimos, se les llama estafilococos; también se pueden agrupar en pares que reciben el nombre de diplococos. Las bacterias en forma de bastón reciben el nombre de bacilos. Si al teñirlos con el Gram quedan de color rojo, se les denomina gramnegativos. Los bacilos curvados que presentan espirales se llaman espirilos, rígidos; algunas 


\section{Biotecnología y su incidencia en el estudio de las bacterias}

Vol. 3, núm. 3., (2019)

Karen Bayas Villagómez; Valeria Lorena Segarra Zambrano; Jefferson Arsenio Siguachi Quinteros, Karla Marilyn Obando Cuero

bacterias en espiral presentan formas fácilmente reconocibles, como las espiroquetas, semejantes a un tornillo o sacacorchos, flexibles. Las bacterias que carecen de pared celular tienen gran plasticidad (micoplasmas) y adoptan una variedad de formas. Las bacterias esféricas tienen un tamaño promedio de 1 micrómetro de diámetro, mientras que los bacilos miden 1.5 de ancho por 6 micrómetros de largo, a continuación, se presenta la figura $\mathrm{n}^{\circ} 3$ con la finalidad de ofrecer una imagen de las diferentes formas de bacterias.

Figura $\mathbf{N}^{\circ} \mathbf{3}$ Formas de las Bacterias

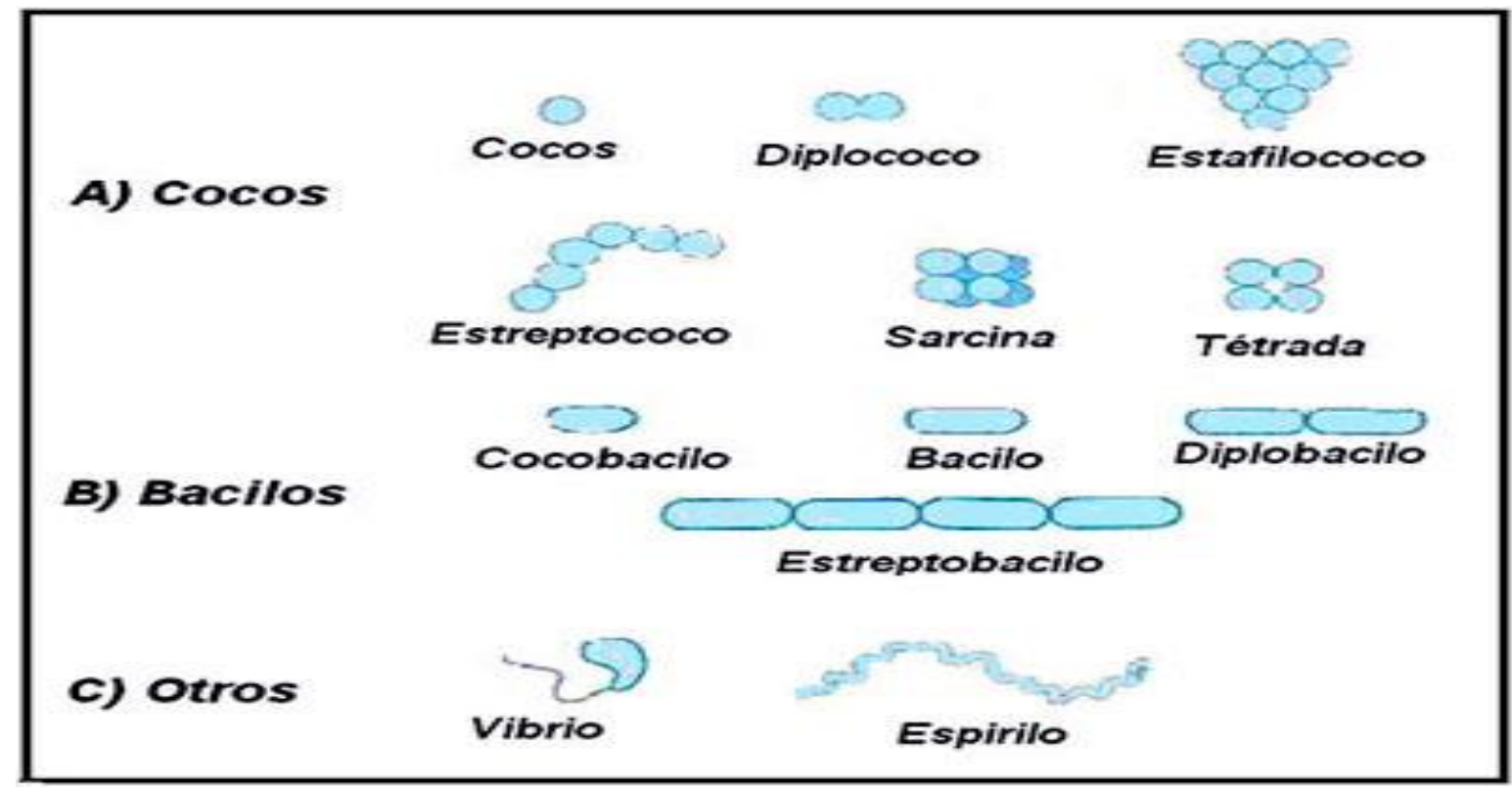

Fuente: Calvo (ob.cit)

Es importante acotar que, las bacterias son un grupo amplio de organismos unicelulares. Pueden vivir en diferentes partes del cuerpo. Algunos tipos de bacterias son inofensivos e incluso beneficiosos. Otros causan infecciones y enfermedades. Una prueba de cultivo de bacterias puede detectar bacterias perjudiciales en el cuerpo. Durante una prueba de cultivo de bacterias, se toma una muestra de sangre, orina, piel u otra parte del cuerpo. El tipo de prueba depende del lugar en el que se sospecha la infección. Las células de la muestra se llevan a un laboratorio y se colocan en un medio especial para promover la reproducción celular. Los resultados generalmente están 


\section{Biotecnología y su incidencia en el estudio de las bacterias}

Vol. 3, núm. 3., (2019)

Karen Bayas Villagómez; Valeria Lorena Segarra Zambrano; Jefferson Arsenio Siguachi

Quinteros, Karla Marilyn Obando Cuero

listos en pocos días. Sin embargo, algunos tipos de bacterias se reproducen lentamente y los resultados pueden tardar varios días o más.

Entre los tipos de cultivos que incorpora la medicina para lograr un respectivo tratamiento al paciente, en función a la enfermedad que manifiesta, se encuentran un grupo de cultivos considerado, visto por Calvo (ob.cit) de la siguiente manera:

Cultivo de Garganta: Se usa para diagnosticar o descartar una infección de garganta estreptocócica. Procedimiento de la prueba: El médico inserta un hisopo especial en la boca para obtener una muestra de la parte trasera de la garganta y las amígdalas.

Cultivo de Orina: Se usa para diagnosticar una infección del tracto urinario e identificar la bacteria causante de la infección Procedimiento de la prueba: Usted da una muestra estéril de orina en un recipiente siguiendo las instrucciones de su profesional de la salud.

Cultivo de Esputo: El esputo es una mucosidad espesa que se expectora de los pulmones. Es diferente de un escupitajo o de la saliva. Se usa para diagnosticar infecciones bacterianas en las vías respiratorias, por ejemplo, neumonía y bronquitis bacterianas.

En razón de lo anterior, se puede visualizar que, mediante la realización de los diferentes cultivos de bacterias, en el laboratorio las ciencias médicas logran mediante la atención respectiva del paciente, ubicar el tipo de bacteria que se hace presente en la sintomatología presentada, para luego ofrecer el respectivo antibiótico y curar al paciente. Es allí, donde la biotecnología, se precisa como una vía de importancia para este proceso, pues, su intervención oportuna en la investigación, proporciona nuevas informaciones que dan origen a otros antibióticos de mejor competencia para el abordaje médico en cuanto a la enfermedad manifestada por el paciente.

\section{Conclusiones.}

Durante la redacción de los contenidos que complementan el desarrollo del presente artículo, relacionado con la biotecnología y su incidencia en el estudio de las bacterias, se precisar a continuación unas conclusiones generales; entre las cuales se encuentran las siguientes: 


\section{Biotecnología y su incidencia en el estudio de las bacterias}

Vol. 3, núm. 3., (2019)

Karen Bayas Villagómez; Valeria Lorena Segarra Zambrano; Jefferson Arsenio Siguachi

Quinteros, Karla Marilyn Obando Cuero

Al hacer referencia a la biotecnología, se puede comprender que la misma presenta para el área de la salud un aporte significativo, pues, sus investigaciones altamente científicas y modernas ofrecen nuevas acciones o estrategias para el tratamiento de las enfermedades originadas por la actuación de las bacterias. Pues, sus trabajos se encuentran determinados por la utilización de seres vivos sencillos (bacterias y levaduras) y células eucariotas en cultivo, cuyo metabolismo y capacidad de biosíntesis se utilizan para la fabricación de sustancias específicas aprovechables por los individuos.

Asimismo, se puede decir que la biotecnología moderna, desarrollada a partir de una amplia gama de tecnologías, ha sido motivada por la necesidad de adquirir nuevos tratamientos médicos, lo cual aporta contribuciones excepcionales a la medicina humana y favorece el avance de la ciencia, cuyo progreso establece el paso hacia la medicina personalizada, actividad que cumplió en un campo de cuatro generaciones, con el fin de abarcar los diversos espacios en la vida de los individuos. Es decir, ofrecer estrategias no sólo en el campo de la medicina, sino también en los alimentos y esto hace posible el estudio de las bacterias que afectan a la humanidad mediante la presencia de contagios colectivos, debido a la manipulación de los mismos.

En cuanto al estudio de las bacterias, se hace inminente que, mediante la utilización de la biotecnología, las ciencias médicas, tienen oportunidad de tener informaciones modernas y precisas que le ayudan a resolver problemas, canalizar las situaciones confrontadas con el paciente, de este modo, se estudian sus características mediante técnicas que parte de lo más pequeño a lo más grande complejos estudios moleculares. Dado que la biotecnología, incluye el uso de clonación de ADN.

\section{Bibliografía.}

Alves, J. (2015). Virus y Bacterias . Médica Chile , 147-150.

Barrera, Y. (2017). Investigación Holistica . Valencia : SYPAL.

Cabrera, A. (2016). Microbiología . Salud Pública , 50-56.

Calvo, C. (2016). Plagas y Otras Peste . IMBIOMED, 233-238. 
Biotecnología y su incidencia en el estudio de las bacterias

Vol. 3, núm. 3., (2019)

Karen Bayas Villagómez; Valeria Lorena Segarra Zambrano; Jefferson Arsenio Siguachi

Quinteros, Karla Marilyn Obando Cuero

Carreño, C. (2018). Investigación Documental. Pasos . Mérida : Ariel .

Enfermedades, C. p. (13 de Febrero de 2015). https://www.cdc.gov/spanish/index.html. Obtenido de https://www.cdc.gov/spanish/index.html

Medrano, A. (2015). Biotecnología. Importancia . Educación Médica , 10-16.

Ochoa, K. y. (2015). Epidemiología de las Infecciones Bacterianas en Pacientes con Cirrosis Hospitalaria . Biomédica , 8-12.

Regollo, V. (2016). Fundamentos de la Biotecnología. México: Prince .

Saavedra, N. (2015). Términos Metodológicos . México : Pirámide .

Salud, O. M. (29 de Enero de 2018). https://www.who.int/medicacentro/mens:reliase/2018. Obtenido de https://www.who.int/medicacentro/mens:reliase/2018

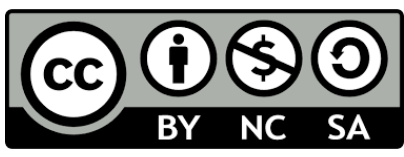

RECONOCIMIENTO-NOCOMERCIAL-COMPARTIRIGUAL

CC BY-NC-SA

ESTA LICENCIA PERMITE A OTROS ENTREMEZCLAR, AJUSTAR Y CONSTRUIR A PARTIR DE SU OBRA CON FINES NO

COMERCIALES, SIEMPRE Y CUANDO LE RECONOZCAN LA AUTORÍA Y SUS NUEVAS CREACIONES ESTÉN BAJO UNA LICENCIA CON LOS MISMOS TÉRMINOS. 